\title{
Aburguesamiento de barrios centrales, un proceso en expansión y mutación
}

\section{Gentrification of central neighborhoods, a process in expansion and mutation}

\author{
Lees, Loreta, Tom Slater y Elvin Wily (2008), Gentrification, \\ Routledge-Taylor \& Francis Group, Nueva York, 3 Io pp., \\ ISBN: D-4I 5-95037-B.
}

Los antiguos barrios obreros y áreas urbanas centrales deterioradas transformadas en barrios residenciales de clase media es, sin duda, el tópico más popular de la investigación urbana anglosajona, y en América Latina es un tema de creciente interés. En nuestra región analizamos si este proceso ocurre en nuestras ciudades, si la importación de teorías y conceptos (como este anglicismo) nos ayudan a comprender procesos de reestructuración de las áreas urbanas centrales y de revaloración de los centros históricos latinoamericanos.

La gentrificación se ha convertido, desde sus orígenes en la década de 1960, en un gran tema de debate e investigación en el mundo entero, particularmente en el anglosajón. Se trata de un tema académico central en muchas disciplinas de las ciencias sociales: geografía, sociología, urbanismo, antropología, politología, economía, etc. Por ello hay una basta literatura (fundamentalmente anglosajona) sobre el tema que abarca libros, revistas y sitios en Internet. Sin embargo, según los autores, no hay un solo libro de texto sobre el tema. Este vacío pretende ser cubierto por la obra que comento.

Los estudios sobre gentrificación aumentaron considerablemente a partir de la década de 1990. Estos trabajos han integrado aportaciones teóricas y evidencias empíricas sobre importantes áreas de investigación urbana: la globalización y las ciudades globales, los cambios en las políticas públicas, las nuevas formas de gestión urbana, la polarización del ingreso, la inequidad, la desigualdad y la exclusión social, la privatización del espacio público, la internacionalización del mercado hipotecario e inmobiliario, los cambios en las formas de consumo, las políticas habitacionales, etc. Así, la gentrificación ha devenido en un concepto clave para examinar de manera transversal una diversidad de fenómenos interconectados en la ciudad y en los barrios centrales.

De acuerdo con los autores, hay varias razones por las que la gentrificación presenta este amplio interés en las ciencias sociales: 1) es un fenó- 
meno urbano nuevo que constituye el más importante aspecto de la reciente reestructuración metropolitana; 2), constituye un desafío para las tradicionales teorías de la localización residencial y la estructura de las ciudades anglosajonas; 3) es un tema que abarca lo político y las políticas públicas e involucra la regeneración urbana y el desalojo de la población pobre; 4) representa una batalla teórica e ideológica para las ciencias sociales, y 5) es un fenómeno mundial ligado a la globalización de la economía. Además, este libro es oportuno por dos razones: porque la gentrificación es un proceso que está mutando y se expande en el mundo para abarcar suburbios y áreas rurales; y porque es un elemento sustancial de los manifiestos de planificación urbana y de la agenda pública, que de manera neutra (con el discurso de la regeneración, el renacimiento, la revitalización o la renovación urbana) pretenden mejorar la economía, el tejido social y físico de las áreas urbanas centrales deterioradas. En síntesis, para los autores, la gentrificación se ha convertido en una estrategia urbana global y en una expresión consumada del urbanismo neoliberal.

\section{El surgimiento de la gentrificación}

La gentrificación es un fenómeno económico, cultural, político y social que básicamente consiste en la revaloración de barrios centrales deteriorados y habitados por población de bajos ingresos, que una vez rehabilitados se destinan a la residencia de clases medias. Evidentemente no se trata de un proceso armónico, sino más bien conflictivo. En este proceso subyace la idea de la distinción de estatus y clase social entre los viejos y los nuevos residentes. La gentrificación nació en ciudades del Primer Mundo en la década de 1960. Sin embargo, estos procesos son antiguos:

- La Haussmannización de París a mediados del siglo xix implicó la demolición de áreas urbanas centrales y el desplazamiento de residentes pobres, para crear modernos bulevares y erigir nuevos edificios y áreas exclusivas para burgueses.

- Federico Engels en La cuestión de la vivienda, en la década de 1880, señala que los barrios de obreros del centro de las grandes ciudades inglesas eran erradicados, para ser reemplazados por nuevos y modernos edificios destinados a otros usos y consumidores.

- En la década de 1950, los programas de renovación urbana de la posguerra destruían viejos barrios centrales en las ciudades de Estados Unidos e Inglaterra, para reemplazar los viejos inmuebles y sustituir a la población pobre por clases medias. El incremento de estas demoliciones dio pauta a las protestas de defensores del patrimonio histórico edificado y al surgimiento de movimientos 
sociales de resistencia y de defensa del derecho a la vivienda y a la ciudad.

A fines de la década de 1970 el futuro del centro de las viejas ciudades industriales anglosajonas parecía incierto y precario. En 1979, la Comisión para la Agenda Nacional del presidente Carter en Estados Unidos advertía que el declive de las áreas urbanas centrales era inevitable: el destino era la muerte del centro. Sin embargo, en los siguientes años, en el marco de la desindustrialización, el discurso sobre el declive fue reemplazado por el de regeneración de las despobladas áreas centrales y el renacimiento urbano. En muchas partes de Estados Unidos se promovió la revitalización del centro de las ciudades y el redesarrollo de brownfields con una estrecha participación del sector privado y el público, y la atracción de las clases medias. Por su parte, el gobierno laborista de Gran Bretaña promovía el programa de renacimiento urbano de las ciudades y pueblos, bautizado por distintos autores como la Carta de la Gentrificación. La Urban Task Force, comisión de expertos creada para el renacimiento urbano, emitió un reporte final lleno de pletóricas y excitantes ideas sobre cómo hacer mejores lugares de las ciudades inglesas: si para el gobierno de Tatcher la regeneración urbana era la medicina adecuada para la degeneración social, el gobierno laborista la veía como la medicina para la depresión urbana.

Para los autores es curioso cómo los gobiernos de Estados Unidos y del Reino Unido se niegan a usar el concepto gentrificación, aunque sus políticas urbanas hagan justamente eso: despojar a los pobres de sus barrios para renovarlos y entregarlos a las clases medias.

\section{Explicaciones basadas en la producción}

Algunos autores se explican el origen y expansión de la gentrificación en función de la economía: la gentrificación es una frontera donde se hacen fortunas. El desarrollo, desinversión y reinversión de determinadas áreas urbanas (donde el capital brinca de un lugar a otro) es un proceso que genera y destruye sus propias oportunidades de desarrollo. Se trata de un proceso en el que las ganancias de la producción industrial comienzan a decaer (primer circuito de inversión), entonces el segundo circuito de inversión, constituido por el mercado inmobiliario y la construcción, se torna atractivo para el gran capital. Sólo así se entendería la dimensión colosal de la renovación y las transformaciones de clase en las áreas urbanas centrales anglosajonas en el siglo xxi. Por ejemplo, en Nueva York el proceso comenzó en el barrio SoHo (al sur de la calle Houston, en el sur de Greenwich Village), pero se expandió a muchos otros barrios centrales. Aquí se intensificó la competencia por la identidad y los nombres de 
moda: SoBro (South of Bronx), SoHa (South of Harlem), Dumbo (Down and Under the Manhattan Bridge) o NoMeat (North of the Meatpacking Distict). ${ }^{1}$ La producción de imágenes y discursos es una faceta importante de la gentrificación que se debe analizar como parte de la producción y reproducción de un orden simbólico.

La teoría de la renta diferencial. Neil Smith señala que el atractivo del suelo urbano reside en su ubicación, accesibilidad, tecnología y trabajo invertidos en su mejoramiento. Es decir, el valor del suelo es una creación social o colectiva: 1) el valor de la centralidad y la accesibilidad es otorgado por la sociedad, y 2) el suelo urbano concentra inversión social acumulada en el transcurso de la historia. Sin embargo, los derechos de propiedad privada permiten a los dueños apropiarse de esa inversión social mediante la captura de una renta base (la que exigen los propietarios por el uso de sus inmuebles). Cada año se incrementan o disminuyen las diferencias entre la renta base y otra potencial, derivada de los posibles usos y aprovechamiento del suelo con nuevos usos y densidades construidas: ésta es la renta diferencial. En este marco, el ciclo de inversiónabandono es una destrucción creativa que redistribuye costos y beneficios entre propietarios. Algunos de ellos no invierten en el mantenimiento de sus inmuebles pues esperan el momento más oportuno para redesarrollar sus propiedades para incrementar sus rentas. La gentrificación ocurre cuando la renta diferencial es mayor y las posibles ganancias se maximizan. Pero estas inversiones no necesariamente ocurren donde el valor del suelo es más bajo, ni el deterioro urbano es mayor, ni en los territorios más pobres o los más abandonados. Desafortunadamente la renta diferencial implica diversos factores que son muy difíciles de medir, pues no hay registros ni bases de datos de los precios del suelo durante décadas. Así, se tienen que construir indicadores específicos para analizar y reconstruir la evolución histórica de las rentas del suelo, los valores del mercado inmobiliario, las mejoras de los barrios, las prácticas tributarias, los subsidios y otros apoyos y proyectos realizados por el gobierno.

\section{Explicaciones basadas en el consumo}

Otros autores aseguran que los procesos de gentrificación tienen su explicación fundamental en los cambios culturales y en las formas de consumo. En este proceso destacan como actores sociales las mujeres, los gays y en general los jóvenes, quienes -se asegura- encontraron en las áreas

\footnotetext{
${ }^{1}$ Con base en datos del Bureau del Censo, los autores señalan que entre 1999 y 2002 en esta ciudad más de 10,000 residentes de las áreas urbanas centrales fueron desplazados mediante acciones públicas y/o privadas; y que otras 39,000 personas se desplazaron por la necesidad de encontrar una vivienda más barata, debido a los incrementos de la renta.
} 
urbanas centrales un entorno más adecuado para su desarrollo que los patriarcales suburbios de baja densidad. En este sentido, se sostiene que la gentrificación es en gran parte resultado del rompimiento de los hogares patriarcales y del surgimiento de hogares de gays, personas solas y parejas de profesionistas, quienes encuentran en las áreas urbanas centrales la posibilidad de eliminar el tiempo de transporte de la vivienda al empleo y de estar cerca de comercios y servicios (lavanderías, restaurantes, guarderías, etcétera). La gentrificación sería más un proceso originado por la nueva composición de hogares, la pérdida de estructuras patriarcales y las formas en que las mujeres se adaptan a los actuales patrones de empleo. Así, la gentrificación no es una cuestión de clase sino de género. En este mismo sentido, otros autores señalan que entre los nuevos residentes de algunos barrios gentrificados predominan electores de izquierda. Se trata de gente liberal, tolerante, políticamente progresista, antirracista, defensores de los derechos humanos y simpatizantes de movimientos de justicia social, que originalmente no pretendían desplazar a ningún antiguo residente de bajos ingresos.

Estas explicaciones se han dirigido a la necesidad de construir una nueva identidad, diferencia y comunidad de la gente que habita los barrios gentrificados. Así, la ciudad central, antítesis de los suburbios, sería la arena de la nueva contracultura para la población femenina, la expresión gay, la creación estética y la experimentación artística. Aquí desfilan varias tesis: Daniel Bell y la sociedad postindustrial, donde los artistas dictan la moda en el consumo cultural más que los medios de comunicación, en un contexto de transición de la industria a los servicios; David Ley, quien asegura que la expansión de la clase media generó la gentrificación; Saskia Sassen, que indica que la polarización social de la ciudad global se deriva de la polarización en el empleo; y Chris Hamnett, para quien la gentrificación se debe a la creatividad de las industrias culturales y a una clase media en expansión.

Género. Para los autores es interesante analizar la relación entre gentrificación y género en la dimensión de la reestructuración social y espacial, y los cambios en los sistemas de reproducción del empleo y población, pues en barrios gentrificados se encuentran muchas mujeres solteras, madres solas, profesionistas y parejas de lesbianas, donde ambas trabajan.

Sexualidad. Castells analizó el papel de la comunidad de gays y lesbianas en la gentrificación del barrio latino en San Francisco, donde la concentración de homosexuales permitió: 1) la generación y consolidación del movimiento de liberación gay en la ciudad; 2) la preservación de la herencia edificada, constituida por bellas casas victorianas, y 3) convertir a la ciudad en un oasis de la tolerancia... a costa de expulsar a la población de bajos ingresos. Richard Florida ha utilizado este hecho para vender su 
discurso que dice que la gentrificación no es mala sino positiva, pues contribuye a fortalecer la diversidad y creatividad que ha guiado el crecimiento de las ciudades. En este mismo sentido se ha señalado que la gentrificación no es sinónimo de genocidio, sino de génesis y de (re) creación.

Etnicidad. En parte es un mito la imagen que indica que la gentrificación está constituida por grupos blancos de clase media que se mueven a barrios ocupados por una alta densidad de minorías étnicas. La clase media negra también gentrifica los barrios de negros y genera el éxodo de negros pobres a las periferias, aunque a menudo este proceso es calificado como de mejoramiento del barrio.

Constitución de clase y estética de la gentrificación. El centro de la ciudad es visto como una marca de distinción y constitución de una identidad diferente a la de los suburbios. La estética de la gentrificación no sólo se ilustra con la dimensión de clase del proceso, sino que abarca la reivindicación del patrimonio histórico: se trata de vender y de comprar historia. Aquí se inscriben los movimientos de retorno al centro de la ciudad y revitalización del barrio como el brownstoning en Nueva York (movimiento pro edificios antiguos de ladrillos oscuros), que era visto como un estilo civilizado de vida y un acto de amor con respecto al patrimonio histórico edificado.

Para los autores aún no se han escrito las experiencias de los desplazados de los barrios gentrificados. En cambio hay toda una narrativa que habla de la obsolescencia (creada casi artificialmente) para remover a los obreros de sus barrios y promover la reconquista de esos sucios barrios industriales en nuevos y bellos paisajes urbanos.

\section{La mutación de la gentrificación}

Para los autores, el mundo anglosajón asiste a la cuarta ola ${ }^{2}$ de gentrificación. En ésta se ha abandonado el referente clásico (la rehabilitación de barrios antiguos, céntricos y decadentes) para masificarse y abarcar nuevos territorios, geografías y formas. Este proceso abarca ahora frentes de agua, áreas urbanas pericentrales, periferias urbanas y áreas rurales; rehabilitación, destrucción y obra nueva; vivienda definitiva, temporal y alojamiento para turistas; centros de convenciones, oficinas, residencias de lujo, distritos gastronómicos y de compras exclusivos y excluyentes, etc. Sin embargo, la constante es el desalojo de los antiguos residentes de bajos ingresos, a quienes se despoja de sus barrios para destinarlos al consumo

\footnotetext{
${ }^{2}$ La primera ola (1968-1972) fue de gentrificación esporádica; la segunda (1978-1988) de expansión; la tercera (1994-1999) de retorno y gran expansión; y la cuarta ola, un proceso en hiperexpansión y mutación.
} 
(ya no sólo a la residencia) de clases medias. En este sentido es lo mismo rehabilitar edificios existentes, que destruirlos y reconstruir un nuevo paisaje urbano con edificios de calidad arquitectónica para destinarlos a la vivienda, comercio o servicios para las clases medias. Hay varios tipos de gentrificación, que por su destino principal puede clasificarse de la siguiente manera:

- La estudiantificación se refiere a la invasión de un gran número de estudiantes de clase media en barrios y pueblos cercanos a una universidad privada.

- La boutiquización es la invasión del pequeño comercio de lujo al menudeo que sustituye la función habitacional de obreros y población de bajos ingresos.

- La turistificación se define como la transformación de barrios en enclaves destinados fundamental o exclusivamente para turistas, a menudo con una oferta de entretenimiento corporativo. La vivienda obrera o popular se sustituye por alojamientos, restaurantes, tiendas y otros servicios para el consumo del turista. Una variante de este proceso es la gentrificación de ciudades costeras: aquí los pueblos de pescadores y aldeas pequeñas se transforman en centros de veraneo y descanso para el consumo de la clase media local e internacional. En estos procesos hay una fuerte participación de las autoridades locales, quienes ven en el turismo una fuente de divisas económicas.

- La gentrificación de las provincias es un proceso que se realiza en cascada, de la gran ciudad (como Londres) hacia las ciudades más pequeñas.

- La gentrificación rural. Se trata de la invasión de clases medias que, en busca de un alojamiento permanente o residencial cerca del campo, desplazan directa e indirectamente a campesinos y residentes de las áreas rurales, por medio del aumento de las rentas y de los precios de las viviendas.

- El nuevo urbanismo colonizador. Se trata del proceso de recuperación o rehabilitación de barrios, pueblos costeros o centros históricos del llamado tercer mundo, para destinarlos fundamentalmente al consumo de clases medias del primer mundo (turistas, residentes permanentes o temporales, inversionistas, etc.). Para los autores, este urbanismo neoliberal, que está afectando a las ciudades del mundo entero, es una forma de neocolonización de las clases medias y la raza blanca. Este hecho demostraría que la gentrificación se ha exportado a nuevos territorios, en la forma de posesiones coloniales en el mundo entero, aquí se privilegia una reapropiación 
sustentable blanca y anglosajona de espacios urbanos y de la memoria histórica.

- La supergentrificación alude a una mayor intensidad de gentrificación que está ocurriendo en algunos barrios selectos de las ciudades globales, como Nueva York. Este proceso involucra un mayor financiamiento privado, un cambio social más fuerte (más desalojos y exclusión) y a una élite globalmente conectada. Los barrios del primer mundo se transforman de manera más radical en enclaves más caros y más exclusivos.

Para los autores, estas formas de gentrificación no son resultado de las preferencias grupales o de clase, ni de la libre oferta y demanda. Es un mito que los deseos de los consumidores son simplemente seguidos por el capital. El gusto de los consumidores por los territorios gentrificados es, en cambio, creado y vendido por poderosos capitalistas, quienes se interesan sobre todo por producir un entorno edificado del que pueden extraer el mayor beneficio posible.

\section{La gentrificación contemporánea}

Ésta es una estrategia urbana global vinculada a la nueva globalización neoliberal y al nuevo urbanismo, donde el gobierno de la ciudad actúa más como un agente empresarial que promueve la acumulación del capital, que como regulador del mercado y protector de residentes desfavorecidos. En gran medida las actuales formas de gentrificación son resultado de la hipermovilidad del capital, la internacionalización de los ciclos de revaloración de territorios urbanos mediante la bursatilización de créditos hipotecarios, el incremento del bienestar de una clase burguesa internacional, así como la liberalización de las barreras económicas y comerciales de los Estados-nación. Aquí el gran capital busca nuevos nichos de mercado en las ciudades y la gentrificación se difunde como una moda cultural y una forma de vida de una clase media internacional (vivir en lofts en el centro de las ciudades). La nueva gentrificación ocurre en diferentes escalas: internacional, nacional, metropolitana e intraurbana. Se trata de nuevos patrones y procesos de inequidad en las ciudades alrededor del mundo.

La cuarta ola de la gentrificación combina un intenso financiamiento de vivienda en régimen de propiedad privada para los hogares de ingresos medios, un nuevo urbanismo conservador basado en una moral invasora que justifica los desplazamientos de población de bajos ingresos, una forma de gestión urbana de corte empresarial que promueve la ciudad para los negocios, y una regulación penal sobre los pobres (siempre sospechosos de cometer actos delictivos). Aquí, el discurso de los conserva- 
dores y de los funcionarios públicos centra el interés de la política en un desarrollo urbano sustentable y evita hablar del tema de las inequidades, del racismo y de la pobreza urbana.

\section{Aspectos positivos y negativos}

La gentrificación tiene aspectos positivos y negativos, como las tesis de la ciudad emancipatoria versus la ciudad revanchista. En la primera ola, los pioneros gentrificadores buscaban y deseaban una mezcla social (y tal vez no deseaban desplazar a la población pobre); en cambio, durante la tercera y cuarta olas los gentrificadores son más individualistas y excluyentes.

Entre los aspectos positivos de la gentrificación los autores destacan la reducción de la expansión urbana y de la subutilización de edificios vacantes, la estabilización de áreas decadentes, la rehabilitación de inmuebles, el incremento de valor en la propiedad privada, el aumento de ingresos fiscales y quizá una mayor mezcla social. Entre los aspectos negativos destacan el desalojo paulatino de la población de bajos ingresos por el incremento de las rentas urbanas, el desplazamiento de comercios y servicios populares, la pérdida de vivienda asequible, la generación de gente sin techo, el resentimiento en los desplazados, la especulación inmobiliaria y en general la pérdida de la diversidad social por la formación de guetos de ricos.

Los autores analizan si la gentrificación, en la forma en que ocurre, realmente presenta aspectos positivos. En principio, si se incrementa el número de residentes que pueden pagar impuestos y comprar bienes y servicios en los barrios otrora deprimidos: 1) esos territorios serían más capaces para financiar vivienda accesible; 2) se mejorarían las oportunidades económicas de los pobres mediante nuevos empleos; 3) los pobres ya no estarían socialmente aislados y tendrían posibilidad de incrementar su educación y capacitación para el empleo; 4) se reduciría la criminalidad, y 5) se podría establecer un nuevo balance entre los nuevos residentes y los pobres y las minorías étnicas. Sin embargo, esto sólo ha ocurrido en el discurso de la política pública que habla de recuperar la diversidad y mezcla social para diluir la concentración de pobreza en áreas urbanas centrales.

En efecto, las políticas de gentrificación son vendidas como inclusivas, armónicas y destinadas a un gran conjunto de población de diferentes ingresos, culturas, edades y estilos de vida. Sin embargo, el discurso de la mezcla social no ocurre ni en los territorios regenerados ni en sus áreas adyacentes. Los conceptos de regeneración, revitalización, renovación, rehabilitación urbana o el movimiento de regreso a la ciudad, describen el mismo fenómeno con un lenguaje empresarial. Pero la gentrificación, 
con o sin función residencial, desaloja y excluye a la población vulnerable y pobre, e implica la pérdida de vivienda asequible.

\section{Colofón}

Este libro recorre cuatro argumentos centrales:

- La gentrificación es un término en los estudios urbanos, por definición político, que involucra el desalojo de clases subalternas y abarca las políticas públicas.

- Los intentos por explicar este fenómeno urbano desde la esfera de la producción o del consumo, han sido superadas. Actualmente el proceso de gentrificación se explica como un fenómeno que abarca la oferta y la demanda, y la producción y el consumo en la esfera económica y cultural.

- Los métodos y las metodologías utilizados por los investigadores están estrechamente vinculados con sus teorías y hallazgos, así como las escalas y dimensiones exploradas. Algunos autores han puesto un gran énfasis en la escala individual y micro (antropólogos), mientras que otros (urbanistas, geógrafos, economistas) analizan la dimensión urbana y económica, por ello, unos presentan la gentrificación como un fenómeno local y otros como un fenómeno en escala metropolitana e internacional.

- Una crítica social expresamente destaca la resistencia a la gentrificación, ese proceso hegemónico. Los tres autores se han involucrado -como académicos o residentes-en actividades antigentrificación en Inglaterra y Estados Unidos. Los tres se reconocen expresamente como escépticos del mundo capitalista y de su respectiva democracia social y económica. Sus críticas abarcan los discursos que hablan de mezcla social y de los beneficios de la gentrificación (que se filtrarían a las clases obreras), porque -argumentan- los beneficios son capturados solamente por las clases medias.

Frente a la inevitable gentrificación y sus recientes mutaciones, los autores pretenden hacer una crítica constructiva. En este sentido no demandan que no se invierta en las áreas urbanas en declive, pero reclaman un renacimiento urbano socialmente justo que involucre financiamiento local y nacional, y participación de la población residente en los procesos de regeneración urbana. En este sentido señalan que se deben reservar y respetar cuotas de vivienda de interés social en los (re)desarrollos urbanos y evitar la segregación socioespacial en beneficio de un desarrollo urbano integral. 
Los autores se proponen hacer la historia de la gentrificación desde el ámbito del barrio hasta la escala global. Como buen libro de texto, cada uno de los siete capítulos que lo integran culmina con una serie de actividades recomendadas (que incluye preguntas, ejercicios, lecturas y análisis de películas y series de televisión como El sexo en la ciudad), para reflexionar y profundizar en los aspectos centrales tratados en cada unidad. Ya no se trata de estudios pioneros que analizan islas de renovación en mares de decadencia urbana, sino de un conjunto de estudios multidisciplinarios que intentan explicar los mares de renovación urbana con islas de decadencia.

El libro es bastante sugerente en ideas, metodologías y evidencias empíricas. Uno no puede dejar de pensar en algunas ciudades mexicanas cuando los autores hablan sobre los tipos de gentrificación que se han alejado de su referente tradicional. ¿¿Un caso típico de desplazamiento de residentes por estudiantes de clase media (estudiantificación) sería la ciudad de Cholula, Puebla, que aloja a alumnos de la Universidad de las Américas? ¿Cuántos centros históricos y aldeas costeras se han boutiquizado y turistificado? ¿Las decenas de casonas antiguas compradas y rehabilitadas por extranjeros para su uso residencial (temporal o permanente) o para destinarse al consumo de turistas en los centros históricos de San Miguel Allende y Mérida, constituyen ejemplos de este nuevo urbanismo colonizador del que hablan los autores?

Víctor Delgadillo-Polanco Universidad Autónoma de la Ciudad de México Correo-e: victor_delgadill@hotmail.com.

Recibido: 11 de enero de 2010. Aceptado: 16 de junio de 2010.

Victor Delgadillo-Polanco. Es doctor en urbanismo por la Universidad Nacional Autónoma de México; maestro en arquitectura y planeación urbana por la Universidad de Stuttgart, Alemania; y arquitecto por la Universidad Autónoma de Puebla. Es miembro del Sistema Nacional de Investigadores (SNI) nivel I, y profesor-investigador de tiempo completo del Colegio de Humanidades y Ciencias Sociales de la Universidad Autónoma de la Ciudad de México. Sus líneas de investigación son patrimonio urbano en América Latina: actores sociales y políticas públicas; políticas de reciclamiento y desarrollo urbano, y vivienda en áreas urbanas centrales. Entre sus publicaciones recientes destacan: "Patrimonio urbano y turismo cultural en la ciudad de México", Andamios, Revista de Investi- 
gación Social, 6 (12), Universidad Autónoma de la Ciudad de México, México, pp. 69-94 (2009); "Cuatro décadas de recuperación del centro histórico de la ciudad de México, del interés público al interés privado", simposio Pasado y presente del patrimonio urbano latinoamericano, Memorias del 53 Congreso Internacional de Americanistas, México, julio de 2009; "Repoblamiento y recuperación del centro histórico de la ciudad de México, una acción pública híbrida, 2001-2006”, Economía, Sociedad y Territorio, viII (28), El Colegio Mexiquense, Zinacantepec, pp. 817-845 (2008). 